\title{
Intranasal fentanyl provides adequate postopera- tive analgesia in pediatric patients
}

\author{
[L'administration intranasale de fentanyl fournit une analgésie postopératoire \\ adéquate chez les patients pédiatriques]
}

Ray Manjushree MBBS MD, Aparna Lahiri MBBS, Bablu Rani Ghosh MBBS DA MD, Arpita Laha MBBS MD, Krishna Handa MBBS

Purpose: To evaluate intranasally administered fentanyl for postoperative analgesia in pediatric patients.

Methods: Thirty-two children aged four to eight years, ASA physical status I and II were included in this prospective randomized controlled study.

In the postoperative care unit, patients were allocated to receive fentanyl, using a double-blind study design, either intranasally (Group I) or intravenously (Group II) in small titrated doses until they became pain free or side effects appeared which prohibited continuation of the drug.

Results: Satisfactory analgesia was achieved in both groups, though the required drug dosage was higher in the intranasal group ( 1.43 $\left.\pm 0.39 \mu \mathrm{g} \cdot \mathrm{kg}^{-1}\right)$. Onset of analgesia tended to be slower via the intranasal route compared to the iv route ( $13 \pm 4.5$ vs $8.3 \pm 3.08$ min; $P=$ not significant). Side effects observed in this series were within an acceptable range and similar for both modalities.

Conclusion: The intranasal route provides a good alternative for administration of fentanyl in pediatric surgical patients.

Objectif : Évaluer l'action analgésique postopératoire du fentanyl administré par voie nasale chez des patients pédiatriques.

Méthode : Trente-deux enfants, de quatre à huit ans et d'état physique ASA l et Il ont participé à une étude prospective, randomisée et controlée. Une fois à la salle de réveil, les enfants ont été répartis au hasard et ont reçu du fentanyl, selon un protocole à double insu, soit par voie nasale (groupe I), soit par voie intraveineuse (groupe II) en petites doses jusqu'à la disparition de la douleur ou l'apparition d'effets secondaires, ce qui commandait l'arrêt du médicament.

Résultats : Une analgésie satisfaisante a été atteinte chez les enfants des deux groupes, bien que la dose nécessaire ait été plus élevée dans le groupe I ( I,43 $\left.\pm 0,39 \mu \mathrm{kg}^{-1}\right)$. L'analgésie a été plus lente à s'installer après l'administration intranasale, comparée à la voie iv ( $13 \pm 4,5$ vs $8,3 \pm 3,08 \mathrm{~min} ; P=$ non significatif). Les effets secondaires observés étaient acceptables et similaires suivant les deux modalités utilisées.

Conclusion : L'administration intranasale de fentanyl constitue une solution de rechange intéressante chez les patients en chirurgie pédiatrique.

A high analgesic efficacy and relatively lower incidence of side effects make fentanyl one of the commonly used opioids in the perioperative period. To avoid painful injections in children alternative noninvasive methods of administration of fentanyl should be explored. Application of opioids to mucosal surfaces to achieve analgesia is not a new concept and fentanyl was found effective when administered by this route. Intranasal fentanyl was first used by Striebel et al. ${ }^{1}$ to provide postoperative analgesia in adult patients by demandadapted technique and the effect was comparable to the $i v$ route.

The aim of this study was to investigate the efficacy of intranasal fentanyl for postoperative analgesia in children and to determine whether this route provides a fast onset of pain relief and allows titration of dose according to the child's needs.

Methods

After obtaining Institutional approval and parental written informed consent, the study was conducted in 40 pediatric patients, aged four to eight years, ASA physical status I or II scheduled for elective surgical

From the Department of Anesthesiology, N.R.S. Medical College, Calcutta, India.

Address correspondence to: Dr. Manjushree Ray, 12/1, A. K. Point, 68B, A.P.C. Roy Road, Calcutta-700 009, India. Phone: 91-33-

350-6943; Fax: 91-33-246-7722; E-mail: manjushriray@hotmail.com

Accepted for publication July 4, 2001.

Revision accepted November 15, 2001.

CAN J ANESTH 2002/49:2/pp 190-193 
procedures of one to one and half hour duration. Children requiring surgery such as orchiopexy, herniorrhaphy, cystoscopy-fulguration, urethroplasty or appendectomy were selected for this prospective, randomized and blinded study. Patients having a nasal infection or any other nasal pathology were excluded from the study.

Patients were fasted for three to four hours and premedicated with oral midazolam $0.5 \mathrm{mg} \cdot \mathrm{kg}^{-1}$ of body weight. EMLA ${ }^{\circledR}$ cream was applied at the proposed site of $i v$ cannulation one hour before surgery.

After applying standard monitors, an $i v$ cannula was inserted and atropine $0.02 \mathrm{mg} \cdot \mathrm{kg}^{-1}$ was administered. General anesthesia was induced with halothane and nitrous oxide in oxygen via face mask. $I V$ vecuronium bromide $0.1 \mathrm{mg} \cdot \mathrm{kg}^{-1}$ was administered to facilitate orotracheal intubation. After intubation anesthesia was maintained with oxygen, nitrous oxide, $0.5 \%$ halothane, and top up doses of vecuronium bromide. Intraoperative analgesia was provided by repeated doses of fentanyl citrate $\left(1 \mu \mathrm{g} \cdot \mathrm{kg}^{-1}\right)$ q $30 \mathrm{~min}$. At the end of the surgical procedure residual neuromuscular blockade was reversed with neostigmine and atropine and patients were transferred to the postanesthetic care unit (PACU).

In the PACU, patients were assessed for intensity of postoperative pain with the Hannallah pain scale ${ }^{2}$ (Table I). Patients with Hannallah pain score 4 or more were included in this study and randomly allocated to receive fentanyl citrate by the intranasal route (Group I) or the $i v$ route (Group II).

In Group I, $0.5 \mu \mathrm{g} \cdot \mathrm{kg}^{-1}$ fentanyl citrate was administered intranasally. To maintain blinding, an equal volume of normal saline was administered intravenously. Similarly, Group II patients received $0.5 \mu \mathrm{g} \cdot \mathrm{kg}^{-1}$ fentanyl intravenously and the same volume of normal saline intranasally. Each intranasal as well as $i v$ dose was given within $15 \mathrm{sec}$. These doses were repeated every five minutes until the patient became free of pain or any side effect appeared. Failure to achieve adequate analgesia after $30 \mathrm{~min}$, i.e., after receiving $3 \mu \mathrm{g} \cdot \mathrm{kg}^{-1}$ of fentanyl citrate either intravenously or intranasally was another exclusion criteria and these patients were treated by conventional methods.

During the entire procedure an observer, totally unaware of the nature of the study, monitored heart rate, systolic arterial pressure, respiratory rate, sedation, intensity of pain using the Hannallah scale and hemoglobin oxygen saturation.

All patients were monitored clinically for hemodynamic stability and respiratory adequacy in the recovery room. Patients were also observed for side effects like nausea, vomiting, itching and excessive sedation.
TABLE I Hannallah pain scale

\begin{tabular}{lll}
\hline Observation & Criteria & Points \\
\hline Blood pressure & $\pm 10 \%$ preop & 0 \\
& $>20 \%$ preop & 1 \\
\multirow{4}{*}{ Crying } & > 30\% preop & 2 \\
& Not crying & 0 \\
& Crying but responds to tender & 1 \\
& loving care (TLC) & \\
Movement & Crying and does not respond to TLC & 2 \\
& None & 0 \\
Agitation & Restless & 1 \\
& Thrashing & 2 \\
Posture & Patient asleep or calm & 0 \\
& Mild & 1 \\
& Hysterical & 2 \\
Complains of pain & No special posture & 0 \\
(where appropriate & Holeep, or states no pain & 1 \\
by age) & Cannot localize & 2 \\
& Can localize & 0 \\
\hline
\end{tabular}

TABLE II Demographic profile and preoperative vital signs in two groups

\begin{tabular}{|c|c|c|}
\hline & $\begin{array}{l}\text { Group I } \\
(\text { mean } \pm S D)\end{array}$ & $\begin{array}{l}\text { Group II } \\
(\text { mean } \pm S D)\end{array}$ \\
\hline Age (yr) & $5.6 \pm 1.76$ & $5.8 \pm 2.07$ \\
\hline Weight (kg) & $16.26 \pm 4.65$ & $16.95 \pm 4.5$ \\
\hline Heart rate (beats. $\min ^{-1}$ ) & $109 \pm 9.05$ & $107.3 \pm 15.8$ \\
\hline $\begin{array}{l}\text { Systolic arterial pressure } \\
(\mathrm{mmHg})\end{array}$ & $78.26 \pm 10.45$ & $79.2 \pm 6.64$ \\
\hline $\begin{array}{l}\text { Respiratory rate } \\
\left(\text { breath } \cdot \min ^{-1}\right)\end{array}$ & $29.5 \pm 10.1$ & $30.1 \pm 7.4$ \\
\hline $\mathrm{SpO}_{2}(\%)$ & $98.6 \pm 3.8$ & $98.5 \pm 4.6$ \\
\hline
\end{tabular}

$P=$ not significant.

Results are expressed as mean values \pm SD. To analyse differences between the two groups for demographic profile, intensity of pain, onset of analgesia and requirement for fentanyl, Student's $t$ test was used. Chi square test was used for qualitative data. A $P<0.05$ was considered statistically significant.

Results

Although 40 patients were included initially, eight were excluded due to absence of postoperative pain with a score of 4 . The demographic characteristics of the remaining 32 patients are shown in Table II. The two groups were similar with respect to age, weight, heart rate, systolic arterial pressure, respiratory rate and hemoglobin oxygen saturation (Table II). Before administration of fentanyl, intensity of postoperative pain was also similar in both groups ( $P=$ not significant; Table III). 
TABLE III Postoperative pain scoring in two groups

\begin{tabular}{lllll}
\hline & \multicolumn{4}{l}{ Duration after administration of fentanyl (min) } \\
& 0 & 5 & 10 & 15 \\
\hline Group I & $5.73 \pm 1.3$ & $3.2 \pm 2.7$ & $1.3 \pm 1.7^{* *}$ & $0.2 \pm 0.4^{* * *}$ \\
Group II & $5.33 \pm 2.3$ & $2.3 \pm 2.1$ & $0.73 \pm 0.7^{* * *}$ & $0.2 \pm 0.56^{* * *}$ \\
\hline${ }^{* *} P<0.01 ;{ }^{* *} P<0.001$. & & &
\end{tabular}

TABLE IV Postoperative side effects in the two groups

\begin{tabular}{lll}
\hline Side effects & $\begin{array}{l}\text { Group I } \\
\text { intranasal fentanyl } \\
\text { Number of patients (\%) }\end{array}$ & $\begin{array}{l}\text { Group II } \\
\text { IV fentanyl }\end{array}$ \\
\hline Dizziness & $1(6)$ & - \\
Nausea & - & $1(6)$ \\
Vomiting & - & - \\
Pain / Burning in nose & - & - \\
Itching & - & - \\
Euphoria & - & - \\
Hypoxia $\left(\mathrm{Spo}_{2}<90 \%\right)$ & $2(12)$ & $1(6)$ \\
\hline
\end{tabular}

$P=$ not significant.

Patients in the intranasal group required significantly more fentanyl $\left(1.43 \pm 0.39 \mu \mathrm{g} \cdot \mathrm{kg}^{-1}\right)$ than those in the iv group $\left(0.8 \pm 0.3 \mu \mathrm{g} \cdot \mathrm{kg}^{-1}\right)$ for postoperative analgesia $(P<0.001)$. Total requirement of fentanyl citrate was $21.43 \pm 10.5 \mu \mathrm{g}$ and $14.6 \pm 6.35 \mu \mathrm{g}$ in the intranasal and $i v$ groups respectively $(P<0.01)$. Within ten minutes, pain scores were significantly reduced in both groups (Table III) and there was no need to discontinue the study in any patient because of insufficient pain relief after $30 \mathrm{~min}$. Complete analgesia was achieved within $13.0 \pm 4.5 \mathrm{~min}$ in the intranasal group compared to $8.3 \pm 3.08 \mathrm{~min}$ in the $i v$ group ( $P=$ not significant).

Occurrence of side effects was also similar in the two groups (Table IV). Three patients became hypoxic in this series but they responded well to oxygen therapy.

Discussion

Our results show that intranasal fentanyl is quite effective in relieving pain in pediatric patients. Though onset was marginally slower compared to the iv route, it remained within an acceptable range. Most patients experienced significant pain relief within ten minutes and became totally pain free in $13.0 \pm 4.5 \mathrm{~min}$. Different drugs such as midazolam, ${ }^{3}$ sufentanil ${ }^{4}$ and ketamine have been used intranasally in pediatric patients to provide either sedation or analgesia and this route was found to be as effective as the iv route. Wilton et al. ${ }^{3}$ demonstrated the calming effect of intranasal midazolam within five to ten minutes. This rapid onset of action was also confirmed by Walbergh et $a l^{5}$ who showed peak plasma concentrations of midazolam in $10.2 \pm 2.0 \mathrm{~min}$ after intranasal administration.

Although the pharmacokinetics of fentanyl by the intranasal route have not been evaluated, lipophilic agents with a low molecular weight produce plasma levels similar to those achieved by the $i v$ route. ${ }^{6}$ Thus, fentanyl might exhibit a similar pharmacokinetic profile when administered intranasally and intravenously.

Quality of analgesia following intranasal administration was comparable to that after $i v$ administration, but doses required were significantly increased. Our observation differs from that reported by Striebel and co-workers. ${ }^{7}$ Requirement of drug by the intranasal route was almost the same as that by the $i v$ route in their series. A possible reason may be the way we administered the drug. In the present series, the drug was instilled in the nasal cavity drop by drop with a needle and syringe while Striebel ${ }^{7}$ and other investigators used a spray. Therefore, dispersion of the drug in small particles and subsequent absorption and bioavailability was probably enhanced in their series. Helmers $^{8}$ and Vercauteren ${ }^{9}$ also suggested a higher bioavailability of sufentanil after intranasal administration. This higher bioavailability is due to direct entrance of the drug into the systemic circulation and avoidance of the hepatic first-pass effect.

Intranasal fentanyl does not irritate the nasal mucosa and has a very low ciliotoxic effect, hence the drug may be used for prolonged periods without any adverse effect. ${ }^{10}$ None of our patients complained of pain or burning sensation in the nose following instillation of fentanyl.

Side effects such as nausea, vomiting and hypoxia observed in this series, were within an acceptable range and responded well to conventional therapy. One patient in the $i v$ group and two in the intranasal group became hypoxic $\left(\mathrm{SpO}_{2}<90 \%\right)$. They were treated successfully by nasal oxygen. Respiratory depression was not apparent in these patients either in the form of low respiratory rate or tidal volume. Hence, fentanyl was possibly not the cause of hypoxia.

In summary, intranasal and $i v$ fentanyl both provide effective postoperative analgesia in pediatric patients and their safety profile is similar.

\section{References}

1 Striebel HW, Koenigs D, Krämer J. Postoperative pain management by intranasal demand-adapted fentanyl titration. Anesthesiology. 1992; 77: 281-5.

2 Hannallah RS, Broadman LM, Belman AB, Abramowitz MD, Epstein BS. Comparison of caudal and ilioinguinal/iliohypogastric nerve blocks for control of post-orchiopexy pain in pediatric ambulatory 
surgery. Anesthesiology 1987; 66: 832-4.

3 Wilton NCT, Leigh J, Rosen DR, Pandit UA

Preanesthetic sedation of preschool children using intranasal midazolam. Anesthesiology 1988; 69: 972-5.

4 Henderson JM, Brodsky DA, Fisher DM, Brett CM, Herztka RE. Preinduction of anesthesia in pediatric patients with nasally-administered sufentanil. Anesthesiology 1987; 69: 495.

5 Walbergh EJ, Wills RJ, Eckhert J. Plasma concentration of midazolam in children following intranasal administration. Anesthesiology 1991; 74: 233-5.

6 Hussain A, Foster T, Hirai S, Kashibara T, Batenhorst $R$, Jones $M$. Nasal absorption of propranolol in humans (Letter). J. Pharm Sci 1980; 69: 1240.

7 Striebel HW, Pommerening J, Rieger A Intranasal fentanyl titration for postoperative pain management in an unselected population. Anaesthesia 1993; 48: 753-7.

8 Helmers JHJH, Noorduin H, Van Peer A, Van Leeuwen $L$, Zuurmond WWA Comparison of intravenous and intranasal sufentanil adsorbtion and sedation. Can J Anaesth 1989; 36: 494-7.

9 Vercauteren M, Boeckx E, Hanegreefs G, Noorduin H, Vanden Bussche $G$ Intranasal sufentanil for pre- operative sedation. Anaesthesia 1988; 43: 270-3.

10 Peng PWH, Sandler AN. A review of the use of fentanyl analgesia in the management of acute pain in adults. Anesthesiology 1999; 90: 576-99. 